\title{
Mapping localised freshwater anomalies in the brackish paleo-lake sediments of the Machile-Zambezi Basin with transient electromagnetic sounding, geoelectrical imaging and induced polarisation
}

Chongo, Mkhuzo; Christiansen, Anders Vest; Fiandaca, Gianluca; Nyambe, Imasiku A.; Larsen, Flemming; Bauer-Gottwein, Peter

Published in:

Journal of Applied Geophysics

Link to article, DOI:

10.1016/j.jappgeo.2015.10.002

Publication date:

2015

Document Version

Peer reviewed version

Link back to DTU Orbit

Citation (APA):

Chongo, M., Christiansen, A. V., Fiandaca, G., Nyambe, I. A., Larsen, F., \& Bauer-Gottwein, P. (2015). Mapping localised freshwater anomalies in the brackish paleo-lake sediments of the Machile-Zambezi Basin with transient electromagnetic sounding, geoelectrical imaging and induced polarisation. Journal of Applied Geophysics, 123, 81-92. https://doi.org/10.1016/j.jappgeo.2015.10.002

\section{General rights}

Copyright and moral rights for the publications made accessible in the public portal are retained by the authors and/or other copyright owners and it is a condition of accessing publications that users recognise and abide by the legal requirements associated with these rights.

- Users may download and print one copy of any publication from the public portal for the purpose of private study or research.

- You may not further distribute the material or use it for any profit-making activity or commercial gain

- You may freely distribute the URL identifying the publication in the public portal 
1 Mapping localized freshwater anomalies in the brackish Paleo-Lake sediments of the Machile-

2 Zambezi Basin with transient electromagnetic sounding, geoelectrical imaging and induced 3 polarization

5 Mkhuzo Chongo ${ }^{1, *}$, Anders Vest Christiansen ${ }^{2}$, Gianluca Fiandaca ${ }^{2}$, Imasiku A Nyambe ${ }^{3}$,

6 Flemming Larsen ${ }^{4}$ and Peter Bauer-Gottwein ${ }^{1}$

$8{ }^{1}$ Technical University of Denmark, Department of Environmental Engineering, Miljøvej, Building 9 113, 2800 Kgs. Lyngby, Denmark

10 22Aarhus University, Department of Geoscience, C.F. Møllers Alle 4, 8000-Århus C, Denmark

$11{ }^{3}$ University of Zambia, School of Mines, Department of Geology, Great East Road Campus, P.O 12 Box 32379, Lusaka, Zambia

$13{ }^{4}$ Geological Survey of Denmark and Greenland (GEUS), Geochemistry, Øster Volgade 10, 1350 14 København K, Denmark

16 *Corresponding author email: mkhuc@env.dtu.dk

19 A recent airborne TEM survey in the Machile-Zambezi Basin of south western Zambia revealed 20 high electrical resistivity anomalies (around $100 \Omega \mathrm{m}$ ) in a low electrical resistivity (below $13 \Omega \mathrm{m}$ ) 
21 background. The near surface (0-40 m depth range) electrical resistivity distribution of these 22 anomalies appeared to be coincident with superficial features related to surface water such as

23 alluvial fans and flood plains. This paper describes the application of transient electromagnetic 24 soundings (TEM) and continuous vertical electrical sounding (CVES) using geo-electrics and time 25 domain induced polarization to evaluate a freshwater lens across a flood plain on the northern bank of the Zambezi River at Kasaya in south western Zambia. Coincident TEM and CVES measurements were conducted across the Simalaha Plain from the edge of the Zambezi River up to $6.6 \mathrm{~km}$ inland. The resulting TEM, direct current and induced polarization data sets were inverted using a new mutually and laterally constrained joint inversion scheme. The resulting inverse model sections depict a freshwater lens sitting on top of a regional saline aquifer. The fresh water lens is

31 about $60 \mathrm{~m}$ thick at the boundary with the Zambezi River and gradually thins out and deteriorates in water quality further inland. It is postulated that the freshwater lens originated as a result of interaction between the Zambezi River and the salty aquifer in a setting in which evapotranspiration is the net climatic stress. Similar high electrical resistivity bodies were also associated with other surface water features located in the airborne surveyed area.

Key words:

TEM; DCIP; Joint Inversion; surface water/ groundwater interaction; Zambezi River; Zambia

41 The interaction between surface water and groundwater has been studied extensively around the world (Milosevic et al., 2012; Shanafield and Cook, 2014; Sophocleous, 2002; Westbrook et al., 
2005; Winter, 1999; Zarroca et al., 2015; Zhou et al., 2014) using different approaches, and increasingly geophysical methods are being incorporated into such studies.

Specific examples of studies that have used geophysical data to investigate hydrogeological phenomenon include Bauer et al. (2006) who described the process of salt accumulation on islands within the Okavango Delta, related to the interaction between surface water and groundwater under evapo-concentration using a combination of electrical resistivity tomography (ERT) (which is the same as CVES with respect to geo-electrics) and hydrodynamic modeling; Sonkamble et al. (2014) who evaluated the extent of aquifer pollution from industrial effluent across the flood plain of the Palar River at Ambur Town (India) using 1D and 2D geo-electrics correlated with in-situ water quality data and ground penetrating radar; Shalem et al. (2014) who studied the interaction of the Alexander River with groundwater as it cuts its way across a mostly sandy Quaternary coastal aquifer on the eastern coast of the Mediterranean Sea; and Zarroca et al. (2014) who evaluated coastal discharge processes at the Peníscola marsh on the Spanish Mediterranean coast using electrical resistivity imaging and temperature, salinity and ${ }^{224} \mathrm{Ra},{ }^{222} \mathrm{Rn}$ tracer tests coupled with petrophysical analysis.

(1)

Thus geophysical techniques such as ERT are well suited for gathering data at high spatial resolution in comparison to for example point measurenments of hydrogeological parameters at sparsely spaced boreholes (Zarroca et al., 2014). An overall assessment strategy using a combination of different geophysical methods and traditional hydrogeological methods can therefore be advantageous (Brodie et al., 2007; Rubin and Hubbard, 2006). In this regard, TEM (Danielsen et al., 2003; Harthill, 1976; Nabighian, 1991; Xue et al., 2012), direct current geoelectrics (DC) (Aizebeokhai, 2010; Dahlin, 2001; Loke, 1999; Loke et al., 2013) and induced 
polarization (IP) (Bertin and Loeb, 1969; Dahlin et al., 2002; Fiandaca et al., 2012; Fiandaca et al., 2013; Titov et al., 2002) techniques are quite suitable for environmental and hydro-geological investigations particularly in sedimentary terrain.

Traditionally, TEM, DC and IP techniques have been deployed separately even for investigations at the same study site (Bauer et al., 2006; Ezersky et al., 2011; Guerin et al., 2001; Nassir et al., 2000; Vaudelet et al., 2011) although it is now common to have instrumentation that measures both DC and IP in the same field setup (Aristodemou and Thomas-Betts, 2000; Marescot et al., 2008). As a result, different types of datasets are quite often generated for the same physical or environmental phenomenon by inverting each type of dataset individually. Nevertheless, major benefits can be derived from joint inversion of different types of data that observe the same phenomenon and can lead to more accurate interpretations. Thus many studies have successfully used one form of joint inversion or another such as DC-TEM (Albouy et al., 2001; Christiansen et al., 2007; Danielsen et al., 2007), and MRS-TEM (Behroozmand et al., 2012; Vilhelmsen et al., 2014). Examples of DCIP joint inversions are scarce in the literature with the normal practice being to independently invert the DC and IP data either as separate inversion jobs or in one inversion job but without any of the datasets influencing the other during the inversion process. Furthermore, joint DCIP-TEM inversions have not been reported in the literature before. This paper therefore presents a first case study of joint inversion of DCIP-TEM data.

The focus of this paper is on local scale electrical resistivity anomalies derived from interpreting regional scale airborne TEM data in terms of surface water/groundwater interaction in the MachileZambezi Basin. The objectives were to describe the occurrence of high electrical resistivity anomalies in the low electrical resistivity background environment of the Machile-Zambezi Basin; 
91 conduct local scale TEM and direct current-induced polarization (DCIP) CVES measurements 92 along a transect cutting across an area exhibiting electrical resistivity anomalies; evaluate the 93 benefits of joint inversion of the local scale TEM and DCIP data in comparison to separate 94 inversions; and to evaluate the inverse resistivity section in terms of surface water groundwater 95 interaction taking place at the local site.

96

972 Materials and methods

$98 \quad 2.1 \quad$ Study site

99 The study area is in the southern central low lying areas of the Machile-Zambezi Basin on the 100 northern banks of the Zambezi River. The area is drained by three main tributaries of the Zambezi 101 River namely Loanja, Machile (or Kasaya) and Ngwezi. The downstream reaches of the Machile 102 and Ngwezi streams respectively flow across seasonally flooded plains as single channels before 103 entering the Zambezi. However the Loanja stream terminates inland to form an inland delta or 104 alluvial fan. The Loanja alluvial fan and the Simalaha flood plain (bound by Kasaya River to the 105 west and the Zambezi River to the south) were the two local areas of interest for this study. 106 However, the combined TEM/CVES transect is reported only for the Simalaha flood plain (Figure 107 1). 


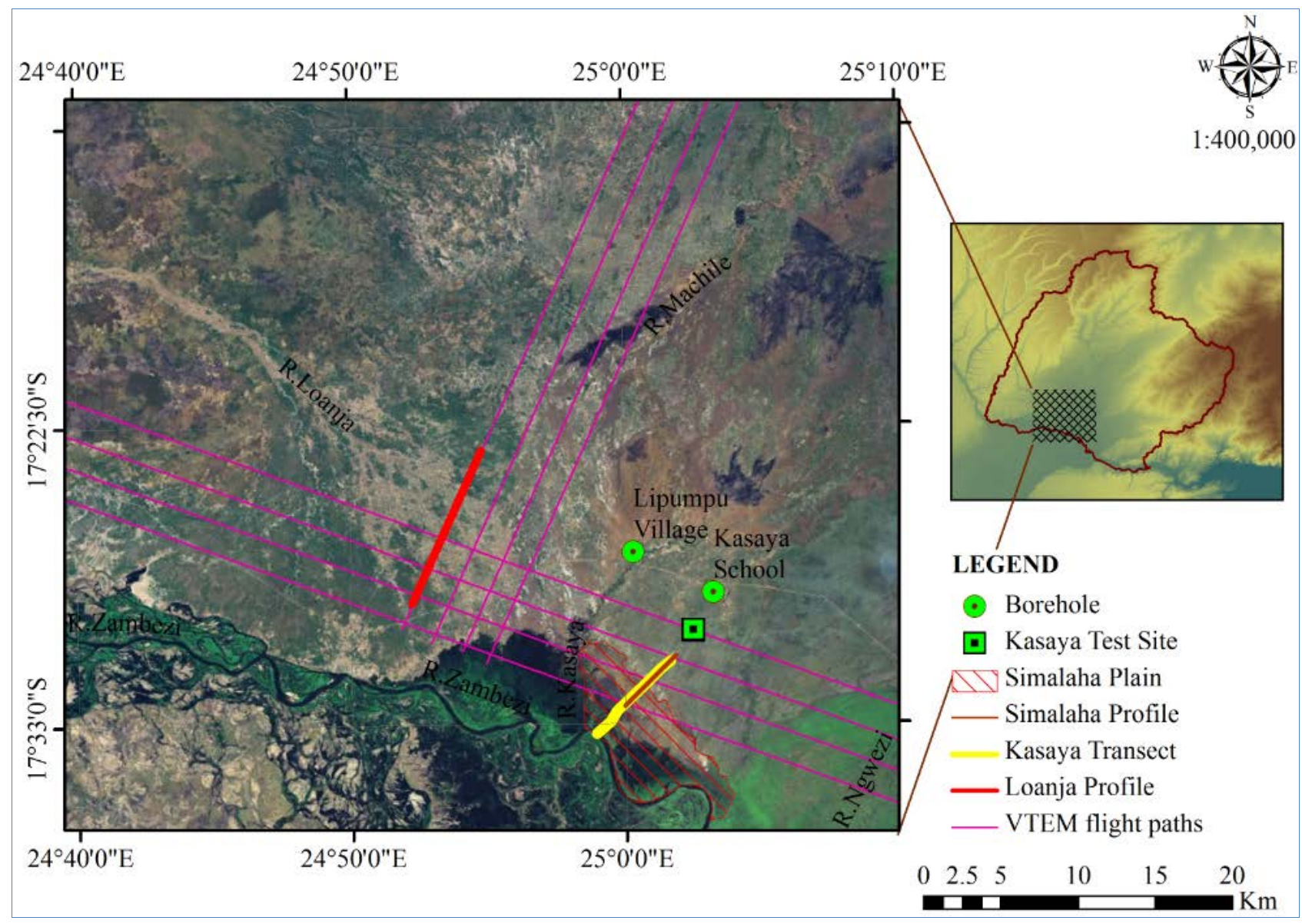

109 Figure 1: The study area depicting Loanja alluvial fan, Simalaha flood plain, Kasaya Transect and

110 TEM flight paths. Satellite image courtesy of ESRI (2014). Note that the Simalaha Profile is shorter

111 than the Kasaya Transect since there is no more airborne electromagnetic data outside the flight 112 lines, whereas the CVES and TEM data on the Kasaya Transect extend beyond the flight path 113 where the Simalaha Profile ends up to the Zambezi River.

\subsection{Data collection and pre-processing}

116 Airborne data was conducted along 8 flight lines totalling 1000 line kilometres using the VTEM 117 system (GEOTECH, 2011). Four of the flight lines were oriented southwest to northeast whereas 118 the other 4 were oriented from northwest to southeast (Figure 1 in Section 2.1). Details about the 119 airborne survey and about the processing, inversion and interpretation of the collected TEM data are 
given in Chongo et al. (2015). Cross sections of the airborne TEM data along the Loanja and

121 Simalaha profiles (Figure 1 in Section 2.1) are shown in Figure 2 (a.) and (b.) respectively. These depict superficial electrical resistivity anomalies in an otherwise low electrical resistivity

123 background (saline environment) and were the basis of the detailed local scale study conducted on

124 the Kasaya transect presented in this paper.

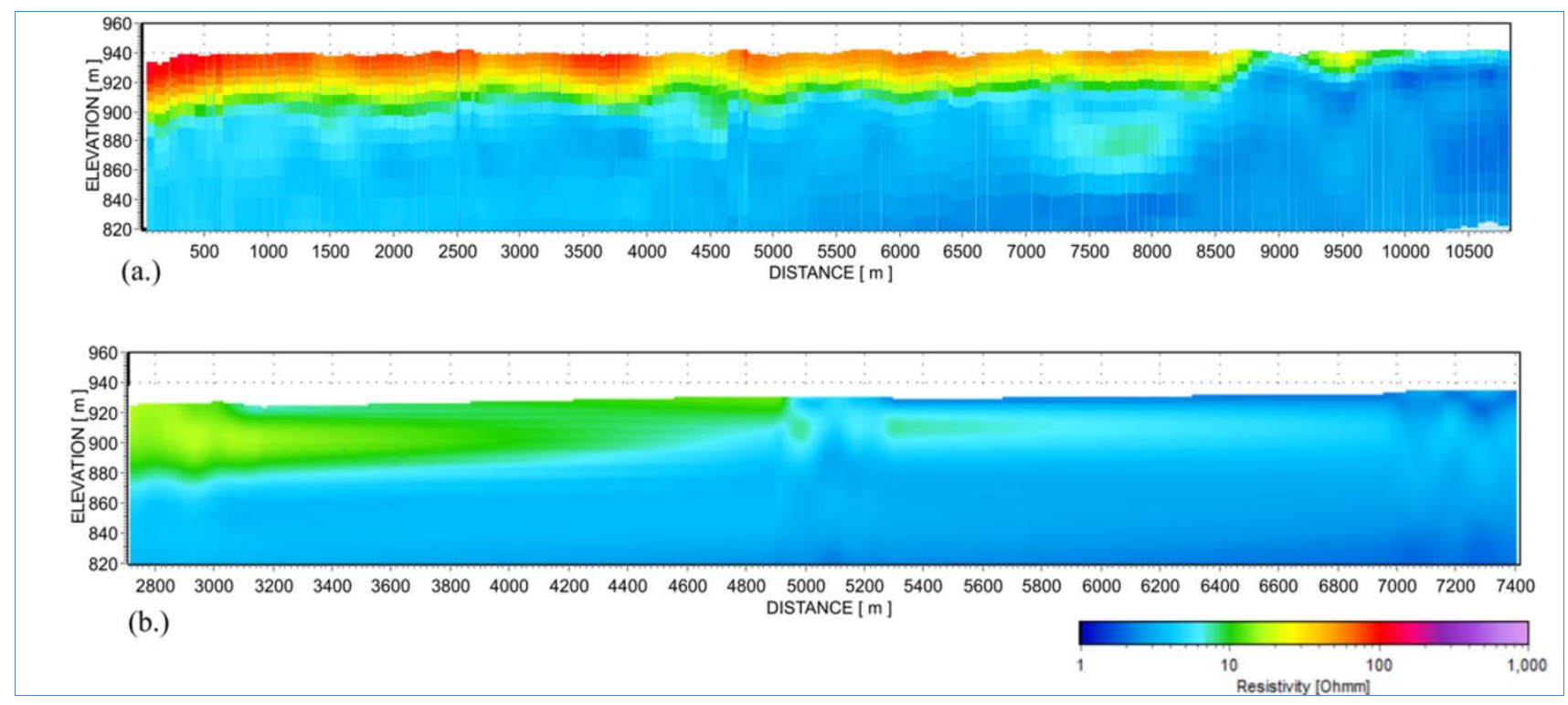

Figure 2: (a) Electrical resistivity cross section along Loanja Profile (Figure 1 in Section 2.1) from the airborne transient electromagnetic data. (b) Interpolated electrical resistivity cross section along

128 Simalaha Profile (Figure 1 in Section 2.1) from the airborne TEM data. Note that Loanja and 129 Simalaha profiles are not drawn to scale nor are they the same length since Loanja Profile (about $130106 \mathrm{~km}$ long) is along a flight line whereas Simalaha Profile (about $5.7 \mathrm{~km}$ long) cuts across flight 131 lines and as a result has a more limited data extent.

133 The detailed local scale geophysical investigation conducted across the Simalaha Plain at Kasaya 134 (Figure 1 in Section 2.1) comprised: 
i. $\quad 6.6$ km of CVES (Loke, 1999; Loke et al., 2013; Nassir et al., 2000) measurements at $5 \mathrm{~m}$ electrode spacing using the gradient array (Dahlin and Zhou, 2006) with 25,003 data points. The Terrameter LS (ABEM(a), 2012) was used for the CVES to measure both direct current electrical resistivity (DC) (Loke et al., 2013) and time domain induced polarisation (IP) (Johnson, 1984) hence the term DCIP to denote the combination of DC and IP measurements in a roll-along setup (information on the transmitter and receiver characteristics of the Terrameter LS is given in Section 2.3 below); and

ii. 64 single site TEM (Christiansen et al., 2006) soundings using the Aarhus University/ABEM WalkTEM system; and another set of 64 central loop TEM soundings using the Geonics ProTEM 47D instrument (Geonics, 2006) at the same positions as the WalkTEM soundings. Thus the total number of TEM soundings along the transect line was 128 spaced at approximately $100 \mathrm{~m}$ along the $6.6 \mathrm{~km}$ transect line per pair of WalkTEM/ ProTEM 47D soundings (information on the transmitter and receiver characteristics of the WalkTEM is given in Section 2.3 below). However data from the ProTEM instrument was not used for this paper.

The DCIP data was pre-processed by removing all data points with negative electrical resistivity and data variations greater than $1.5 \%$. The data that was removed this way represented only $3.3 \%$ of the original data -i.e. 851 filtered out measurements from a total of 25, 857 DCIP measurements.

154 The data set was then imported into the Aarhus Workbench with the IP data gated into 10 channels. 155 Data processing in the Workbench comprised semi-automatic removal of bad IP data by setting a maximum slope change for the IP decay curves followed by visual inspection of the DC and IP data 157 points along the profile and consequent disabling of the outliers. The DCIP noise model was set to 1581.03 uniform standard deviation (USTD) on DC and 1.15 USTD on IP whereas the threshold on 
voltage was set to $2.0 \mathrm{mV}$. For the WalkTEM data we used data from $77.6 \mu$ s to $2.84 \mathrm{~ms}$, focusing on the deep information only.

\subsection{Instrumentation}

As mentioned above, the geophysical equipment used for this paper comprised the Terrameter LS for geo-electric measurenments and the WalkTEM for transient electromagnetic measurenments. Waveform characteristics for the Terrameter LS (ABEM(a), 2012) and the WalkTEM (ABEM(b), 2014) are outlined below in sections 2.3.1 and 2.3.2 respectively.

\subsubsection{Terrameter LS waveform characteristics}

The transmitter waveform of the Terrameter LS was in the form of a square wave and comprised a positive and a negative pulse as shown in Figure 3. The period of the transmitter waveform was automatically determined by the Terrameter LS to be $6.15 \mathrm{~s}$ taking into account the power line frequency of $50 \mathrm{~Hz}$ and DC delay and acquisition times of $0.4 \mathrm{~s}$ and $0.6 \mathrm{~s}$ respectively and the time needed to perform the chargeability measurenments. Thus the transmitter waveform was characterized by a $1 \mathrm{~s}$ positive pulse, followed by an off time of $1.77 \mathrm{~s}$ and then a negative pulse also of $1 \mathrm{~s}$ duration followed by an off time of $2.38 \mathrm{~s}$. IP measurenments were performed during both off times. Self-potential measurenments on the other hand were conducted only during the second off time hence its longer duration. Each measurement comprised at least two cycles so that measured voltages could be averaged in order to eliminate zero shift and linear drift during the measurement cycle (ABEM(a), 2012). Furthermore, the shape of the transmitter waveform prevented polarization from occurring at the electrodes in addition to removing any background voltage or self-potential (Binley and Kemna, 2006). 


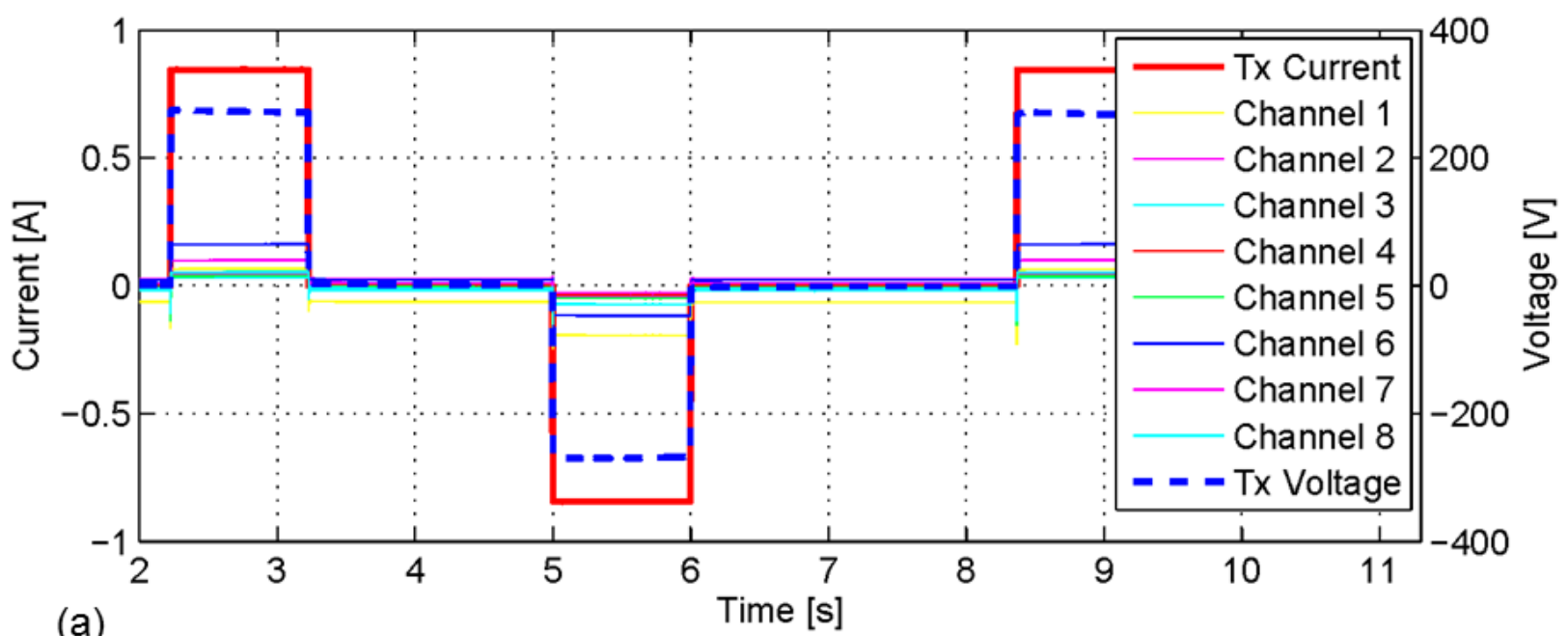

(a)

Time [s]

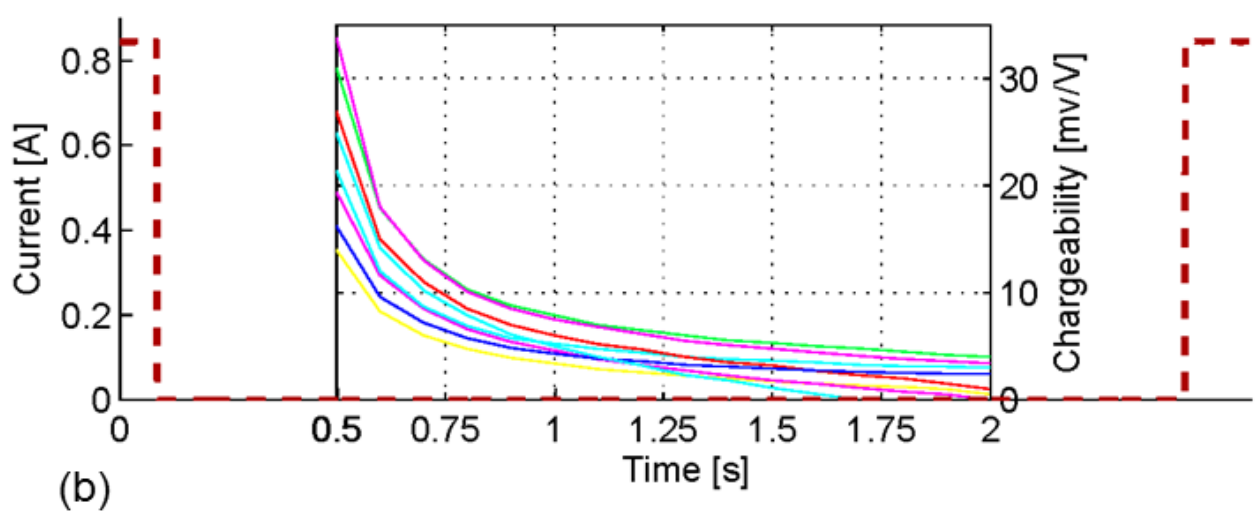

Channel 1

Channel 2

Channel 3

Channel 4

Channel 5

Channel 6

Channel 7

Channel 8

- - - Tx Current

(b)

Figure 3 (a) Terrameter LS transmitter current and voltage waveforms and input voltages from various input channels based on the 4 electrode configuration. (b) Induced polarization decay curves from the various channels of the Terrameter LS measured during transmitter current off time.

The Terrameter LS is a multichannel auto switching instrument which when compared to instruments with separate transmitter/ receiver units has low power, voltage and current ratings of not more than $250 \mathrm{~W}, 1000 \mathrm{~V}$ and 3 Amperes respectively. This is in contrast to the $3000 \mathrm{~V} / 10 \mathrm{~A}$ reachable with separate transmitter/ receiver instruments. However, multichannel auto switching instruments allow for more freedom in the array selection for using arrays with small geometrical factor values (e.g. the gradient array) in comparison with instruments with separate transmitter/ receiver units (i.e. the dipole-dipole configuration). The low geometrical factor values imply higher 
IP voltages sampled by the instruments which partly compensates for the smaller injected current

195 (Gazoty et al., 2013). In addition, processing of the full-decay IP data (as was the case for this paper) allows for the effective deletion of spurious decays such that in the end there is reliable data with multichannel auto-switching instruments also in addition to tomographic coverage.

\subsubsection{WalkTEM waveform characteristics}

200 The WalkTEM instrument utilises a short duration (about $10 \mathrm{~ms}$ ) current pulse to induce eddy 201 currents into the subsurface which in turn generate secondary electromagnetic fields that can be 202 detected by a receiver coil placed at the surface (ABEM(b), 2014; Christiansen et al., 2006; 203 Nabighian, 1991). Characteristic waveforms and earth responses for a TEM sounding depicting the 204 low moment and high moment curves are shown in Figure 4. The low moment is designed 205 obtaining information about the conductivity structure of the shallow subsurface whereas the high moment provides information about the conductivity structure of the deeper subsurface.

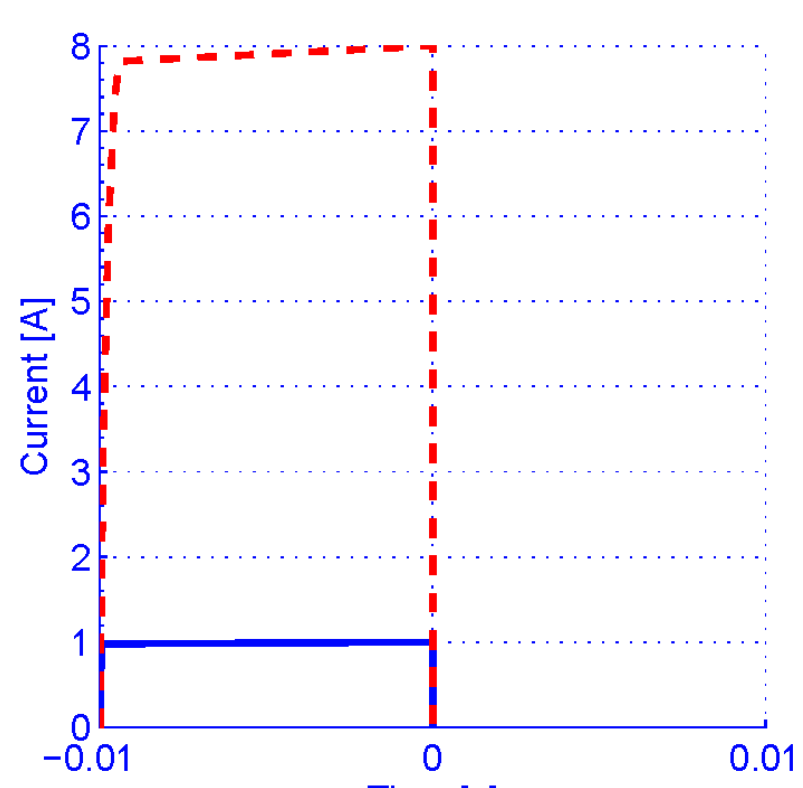

(a)

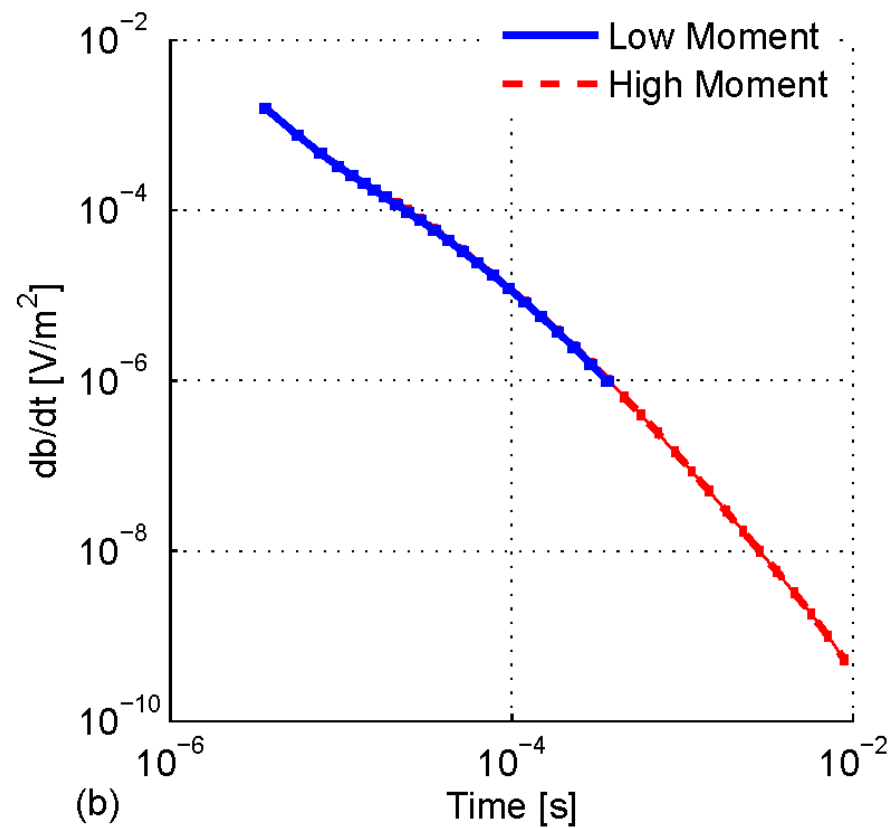

208 Figure 4: (a) WalkTEM transmitter waveform; and (b) Typical earth response. 
211 DC and TEM data were inverted separately using the 1D laterally constrained inversion (LCI) 212 (Auken et al., 2005) scheme. Subsequently, a joint inversion using the mutually and laterally 213 constrained inversion scheme of Christiansen et al. (2007) was conducted on the DC and TEM data 214 as a single inversion. This was then extended to include IP data using the Cole-Cole model setup 215 (Fiandaca et al., 2012; Gazoty et al., 2012b) so that the final inversion was a joint inversion of DCIP and TEM data. Thus the DCIP and TEM model parameters being modelled comprised (intrinsic chargeability $\left(\mathrm{M}_{0}\right)$, frequency dependence constant $(\mathrm{c})$, time constant $(\tau)$, formation electrical resistivity ( $\rho$ ) and layer thicknesses). The inversion algorithm Aarhusinv (Auken et al., 2014) was used for all inversions presented in this paper.

As mentioned in Section 2.2, the interval of TEM soundings along the Kasaya transect was approximately every $100 \mathrm{~m}$ whereas the DCIP data was collected with $5 \mathrm{~m}$ gradient array electrode spacing. The lateral constraints on the TEM models were setup such that each TEM model was constrained only to the adjacent TEM model on either side along the transect line. Similarly, each DCIP model was constrained only to the adjacent DCIP models. Treatment of mutual TEM/DCIP constraints is explained below.

The reference lateral constraint on electrical resistivities was set to 0.3 and scaled according to:

$$
C_{i}=C_{r} * \sqrt{\frac{d}{d_{r}}}
$$

230 where $C_{i}=$ lateral constraint on resistivity [dimensionless fraction]; $C_{r}$ is the reference constraint 231 [dimensionless fraction]; $d$ is the distance between respective models [m]; and $d_{r}$ is the reference 232 distance which was set to $10 \mathrm{~m}$. Furthermore, the reference constraint on depths was set to $1 \mathrm{~m}$ and 
scaled according to depth so that the deeper layers had relatively tighter constraints. The constraint 234 values mentioned above can be considered as medium for the resistivity values and tight for the depths. These were used because they were found to give a reasonable inversion result using trial 236 and error procedure.

Lastly, mutual constraints were applied between the TEM and DCIP models using depths of layers to set the constraint width and scaled according to the power law given above (equation 1). Thus, the deeper layers had wider and tighter constraints between TEM and DCIP models because the constraints were only applied if the distance between respective TEM and DCIP models was less than or equal to the layer depth. The reference constraint between TEM and DCIP models was set to 0.1 but the reference depth was the same as for the lateral constraints (Christiansen et al., 2007).

The petro-physical relation for the Kasaya area was estimated using the following equations (Kirsch, 2009; Mualem and Friedman, 1991; Rhoades et al., 1989),

$$
\sigma_{o}=\frac{\sigma_{w} * \theta^{u}}{\emptyset}+\sigma_{s f c}
$$

250 Where $\sigma_{o}=$ bulk conductivity or formation conductivity $[\mu \mathrm{S} / \mathrm{cm}] ; \sigma_{w}=$ pore water conductivity $251[\mu \mathrm{S} / \mathrm{cm}] ; \theta=$ volumetric water content [dimensionless]; $u=$ exponent on volumetric water content 252 (reported as 2.5 by Kirsch (2009)) $\phi=$ porosity [dimensionless]; $\quad \sigma_{s f c}=$ surface conductivity

$$
\sigma_{s f c}=1000 *(2.3 * C-0.021)
$$


254 unit conversion factor from $\mathrm{mS} / \mathrm{cm}$ to $\mu \mathrm{S} / \mathrm{cm}$ whereas the constants 2.3 and 0.021 are empirical 255 factors as derived by Rhoades et al. (1989).

257 For fully saturated conditions applicable to groundwater, the volumetric water content was taken to 258 be the same as the porosity meaning that Equation 2 could be simplified as:

$$
\sigma_{o}=\sigma_{w} \emptyset^{v}+\sigma_{s f c}
$$

260 where the porosity exponent, $\quad v=u-1$

261 The various parameters of equation 2 and 3 (porosity, porosity exponent and clay content) were 262 adjusted in order to obtain the best curve fitting through the Kasaya pore water point and the 263 unsaturated formation resistivity point Figure 3 (а.). The Kasaya pore water point was defined by 264 the pore water conductivity measured from the borehole fluid by Banda et al. (2014) using an 265 electrical conductivity meter, and the formation electrical resistivity below the water table as 266 measured by the TEM method. The layered earth model derived from 1D inversion of the TEM 267 sounding at Kasaya was comparable to the induction borehole log of Banda et al. (2014) at the 268 Kasaya School borehole Figure 3 (b.). The TEM sounding was conducted using a 40 x 40 m central 269 loop configuration with the centre of the loop coincident with the borehole. The unsaturated 270 formation resistivity point was defined by a pore water electrical conductivity of $0 \mu \mathrm{S} / \mathrm{cm}$, denoting 271 absence of pore water, and the formation electrical resistivity above the water table as measured by 272 the TEM method. 


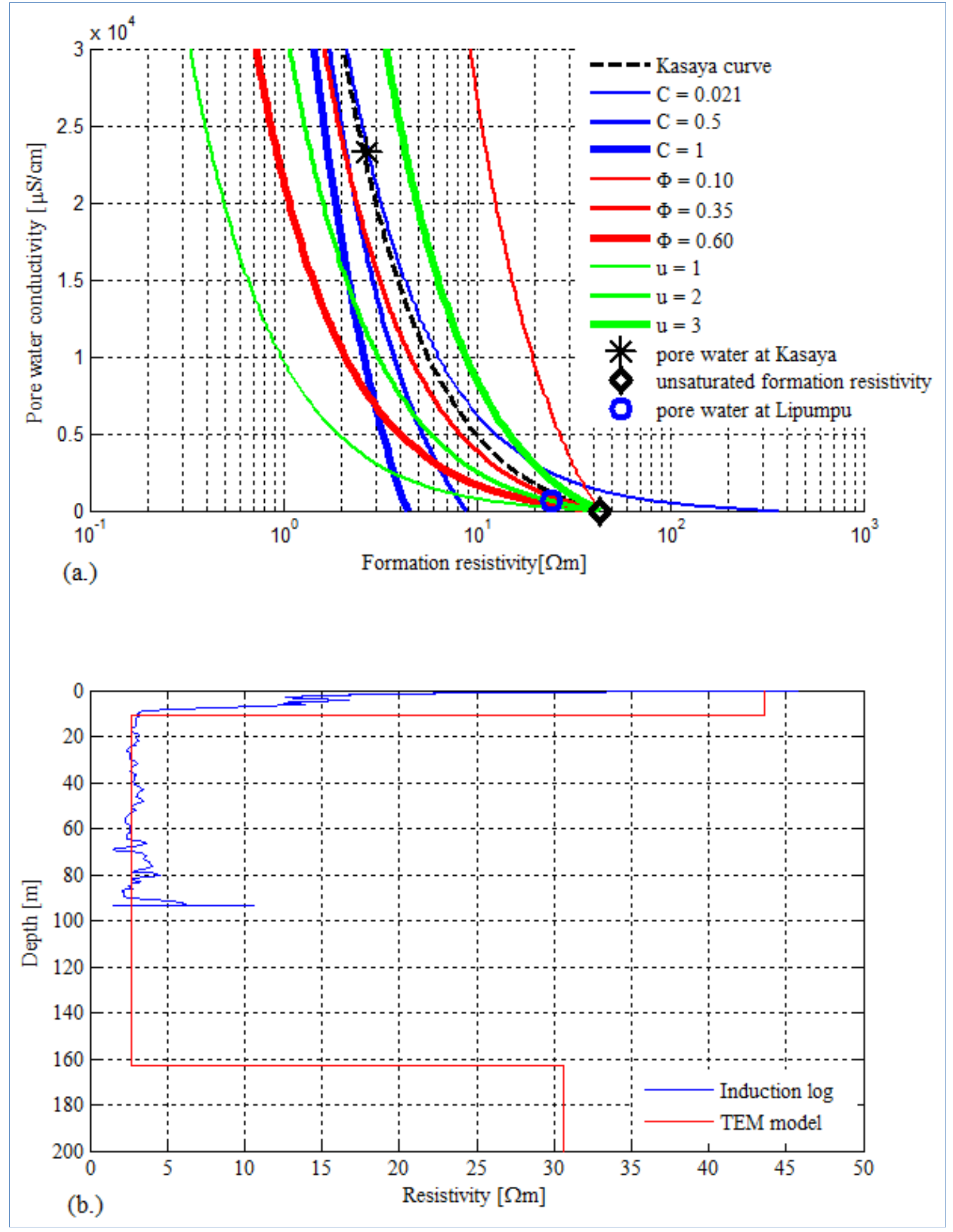

274 Figure 5: (a.) Illustration of the variation of the petro-physical relation (Equation 1) for different 275 parameters (porosity $(\phi)$, volumetic water content exponent (u) and clay content $(\mathrm{C})$. Kasaya curve 
276 is the curve fitting the measured borehole fluid conductivity at Kasaya and the unsaturated 277 formation resistivity measured by TEM at the same location. (b.) Variation of electrical resistivity 278 with depth from an induction log and TEM sounding at Kasaya School in Machile-Zambezi Basin.

280 At present, a petro-physical relationship between IP parameters and hydrogeological parameters is 281 difficult to define. However, Pelton et al. (1978) observed that chargeability (Cole-Cole parameter $282 \mathrm{M}_{0}$ ) and time constant (Cole-Cole parameter $\tau$ ) were directly proportional to fluid concentration and 283 that grain size was inversely proportional and directly proportional to $\mathrm{M}_{0}$ and $\tau$ respectively. On the 284 other hand, Slater and Lesmes (2002) using an experimental laboratory freshwater intrusion into 285 salty water model observed that the chargeability was directly proportional to the fluid resistivity 286 -i.e. inversely proportional to the fluid conductivity in contrast to observations by Pelton et al. 287 (1978). Furthermore, Slater and Lesmes (2002) could not find any clear correlation between 288 chargeability and clay content for various mixtures of sand and bentonite clay. However, a 289 correlation was found to exist between clay content and the product of fluid conductivity and 290 chargeability.

292 Given the observations by Slater and Lesmes (2002), the petro-physical relation given by Equation 293 (2) is assumed to hold for this study, given that the electrical resistivity models produced from the 294 joint DCIP-TEM inversion are informed or constrained by the chargeability models. Further 295 research is required for better treatment of IP parameters with respect to hydrogeological 296 considerations (Gazoty et al., 2012a; Gazoty et al., 2012b; Weller et al., 2013). 


\subsection{Depth of investigation}

299 The depth of investigation (DOI) (Christiansen and Auken, 2012; Oldenburg and Li, 1999; Roy and 300 Apparao, 1971; Spies, 1989) can be used as a way of evaluating the degree to which measured data 301 and their associated uncertainty or noise level are able to resolve the parameters of an inverse 302 layered earth model (Christiansen and Auken, 2012). In this paper, DOI estimation was based on 303 recalculation of the Jacobian matrix of the final 1D inverse model, taking into account the full 304 system transfer function, system geometry, the data and the noise level on the data (Christiansen 305 and Auken, 2012), but not taking into account in the computation the model regularization. From 306 the Jacobian matrix, cumulated sensitivities were computed from which the DOI was deduced based 307 on an empirical cumulative sensitivity threshold value or global threshold (Christiansen and Auken, 308 2012). Two global threshold values were used in this paper: 0.75, for deeper estimation of DOI (or 309 lower DOI) and 1.5, for shallower estimation of DOI (or upper DOI). It should be noted that 310 different DOIs will result for inverse models from different data types based on the same global 311 threshold because the sensitivities of the different data types do not behave in exactly the same way. 312 For example, DC data have higher sensitivities for the shallower subsurface whereas TEM data are 313 more sensitive to conductive layers at greater depth (Christiansen and Auken, 2012). The DOI is 314 presented on the model cross sections in form of colour fading with the upper DOI having a slightly 315 darker shade than the lower. Thus model parameters above the DOI can be said to be well resolved 316 whereas those below it are not. In addition to DOI, data residuals are also typically used as a 317 measure of the fit between the data and the model although the information contained in the data 318 residuals is also implied in the DOI. 
321 As mentioned in Section 2.2, the airborne survey results show electrical resistivity variations correlated with surface water features in both the Simalaha Plain and the Loanja Alluvial Fan (Figure 1 and Figure 2). However, only the results of the Simalaha Profile survey are tackled in this paper.

\subsection{Separate inversions}

LCI of DC (Figure 6 a.) data resulted in a detail of electrical resistivity variations and clearly delineated a conductive layer about $5 \mathrm{~m}$ thick on top of a high electrical resistivity lens that thins out from left to right -i.e. south to north- with respective lowering of electrical resistivity values. The DOI could not go beyond the high resistivity lens especially where the lens was thick and the resistivities relatively very high, but was able to penetrate comparatively deeper where the high resistivity lens had thinned out. In addition, the DOI was very variable along the model cross section and was typically very shallow at both ends, but mostly a few meters less or more than 40 m. The shallow DOI at both ends is a consequence of lack of data in the deeper parts as a result of the four electrode configuration which has a shallower penetration depth for shorter electrode spacing.

LCI of TEM (Figure 6 c.) data shows reduced detail of electrical resistivity variations but improved resolution of electrical resistivity interfaces at depth. The TEM is able to look beyond the high resistivity lens with a much deeper DOI, meaning that model parameters are resolved at larger depths with the TEM data. In addition, the DOI varies more uniformly being deeper at the

342 beginning of the transect line (around $100 \mathrm{~m}$ ) and shallower at the end (around $50 \mathrm{~m}$ ). This variation of DOI is indicative of the sensitivity of the TEM method to conductive layers at depth. At 
344 the beginning of the transect line, the resistive lens is thicker and therefore the depth to the 345 conductive layer is deeper than at the other end of the transect line, where the resistive lens is 346 thinner and the depth to the conductive layer is shallower.
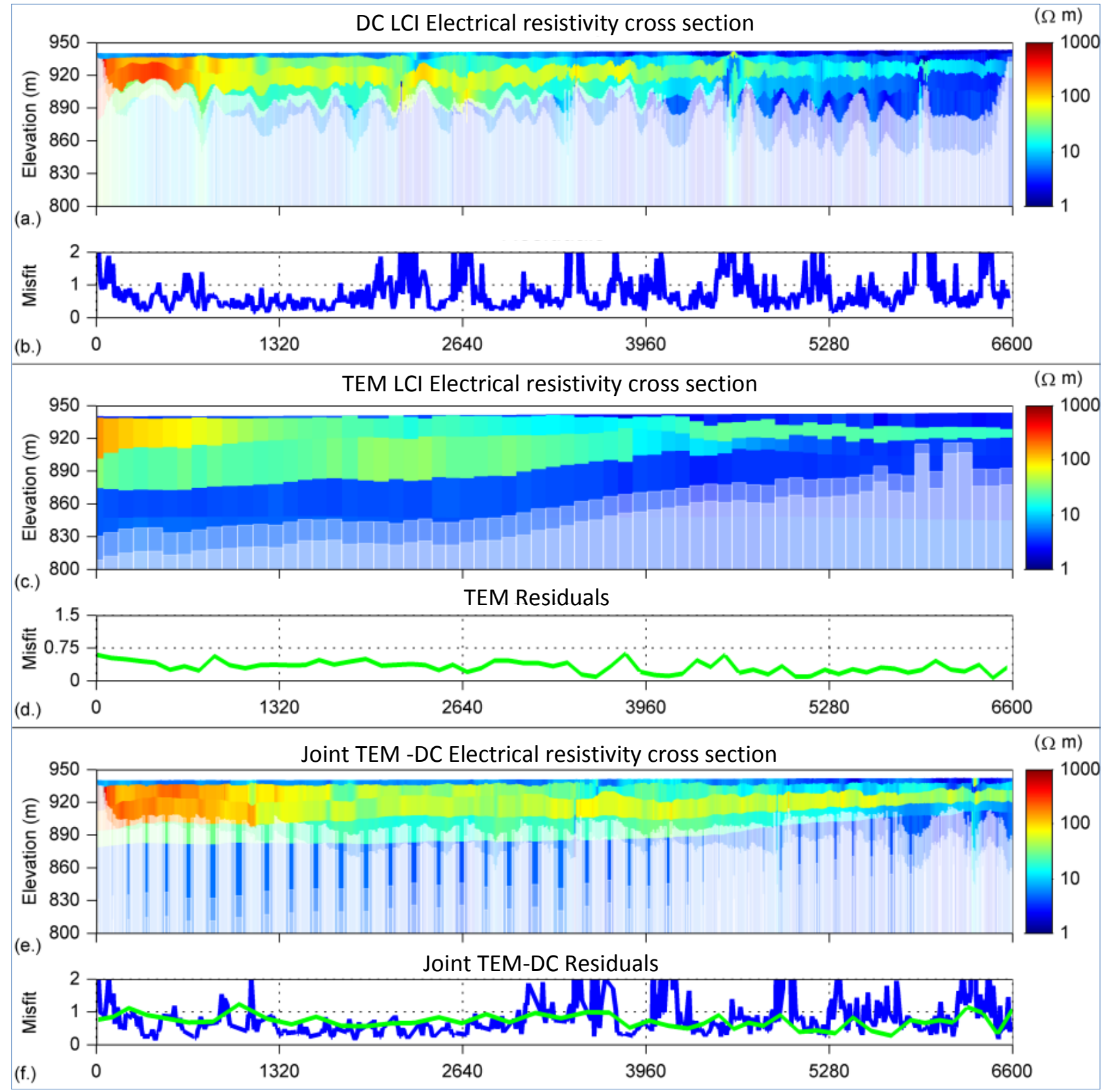

348 Figure 6: Inverse electrical resistivity cross sections and residual plots. (a.) - (b.), inverse electrical 349 resistivity cross section and residual plot respectively for LCI of DC data; (c.) - (d.), inverse 350 electrical resistivity cross section and residual plot respectively for LCI of TEM data; and (e.) - (f.), 
351 inverse electrical resistivity cross section and residual plot respectively for MCI-LCI (i.e. joint 352 inversion) of DC and TEM data. On the residual plots, blue lines are for DC residuals whereas 353 green lines are for TEM residuals.

\subsection{Joint TEM-DC inversions}

356 Evaluation of the inversion result from joint inversion of DC and TEM data (Figure 6 (e.) in Section 357 3.1) shows that major benefits can be derived when TEM and DC data are incorporated into the 358 same inversion job. Variation of DOI for the DC models became much more uniform although it 359 remained at more or less the same level as with the DC only LCI. However, the determination of the 360 depths of different electrical resistivity layers showed a marked improvement in the DC models, 361 which indicates that the characteristic of TEM data to clearly determine layer depths migrated into 362 the DC models during the inversion process. Furthermore the TEM inverse models from the joint 363 inversion still showed a deeper DOI in addition to being in good agreement with the DC data in the 364 upper parts of the section (Figure 6 (e.) in Section 3.1). Thus CVES data was able to improve the 365 resolution of TEM data in the shallow subsurface, whereas TEM data was able to improve the 366 determination of depths, resistivities and thicknesses in the DC data throughout the transect line.

\subsection{Joint TEM DCIP inversions}

369 The results of the Joint TEM-DCIP inversion are shown in Figure7 and Figure 8, with respect to 370 electrical resistivity and chargeability distributions along the Kasaya transect line. Other additional 371 parameters $(\tau$ and $c)$, with the potential of further characterising the aquifer and sediments at 372 Kasaya, were also produced from the DCIP-TEM joint inversion. However these have not been 373 presented or tackled in this paper as doing so would require substantial additional research and 374 analysis beyond the scope of the current study. 


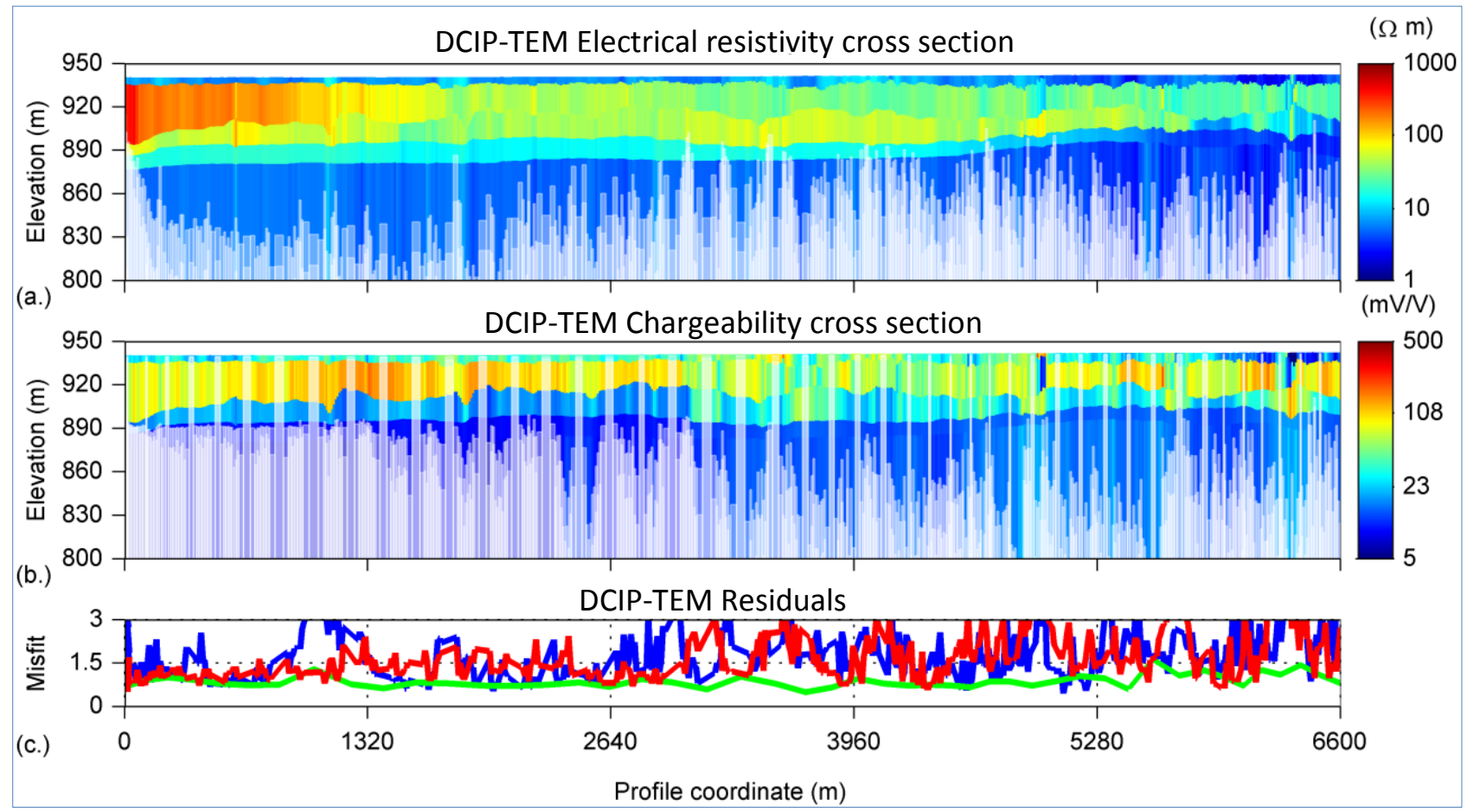

376 Figure 7: (a.) Inverse electrical resistivity cross section, (b.) inverse chargeability cross section, and 377 (c.) data residual plot from joint inversion of DCIP and TEM data. The green line is for TEM 378 residuals whereas the blue and redlines are for DC and IP residuals respectively. 


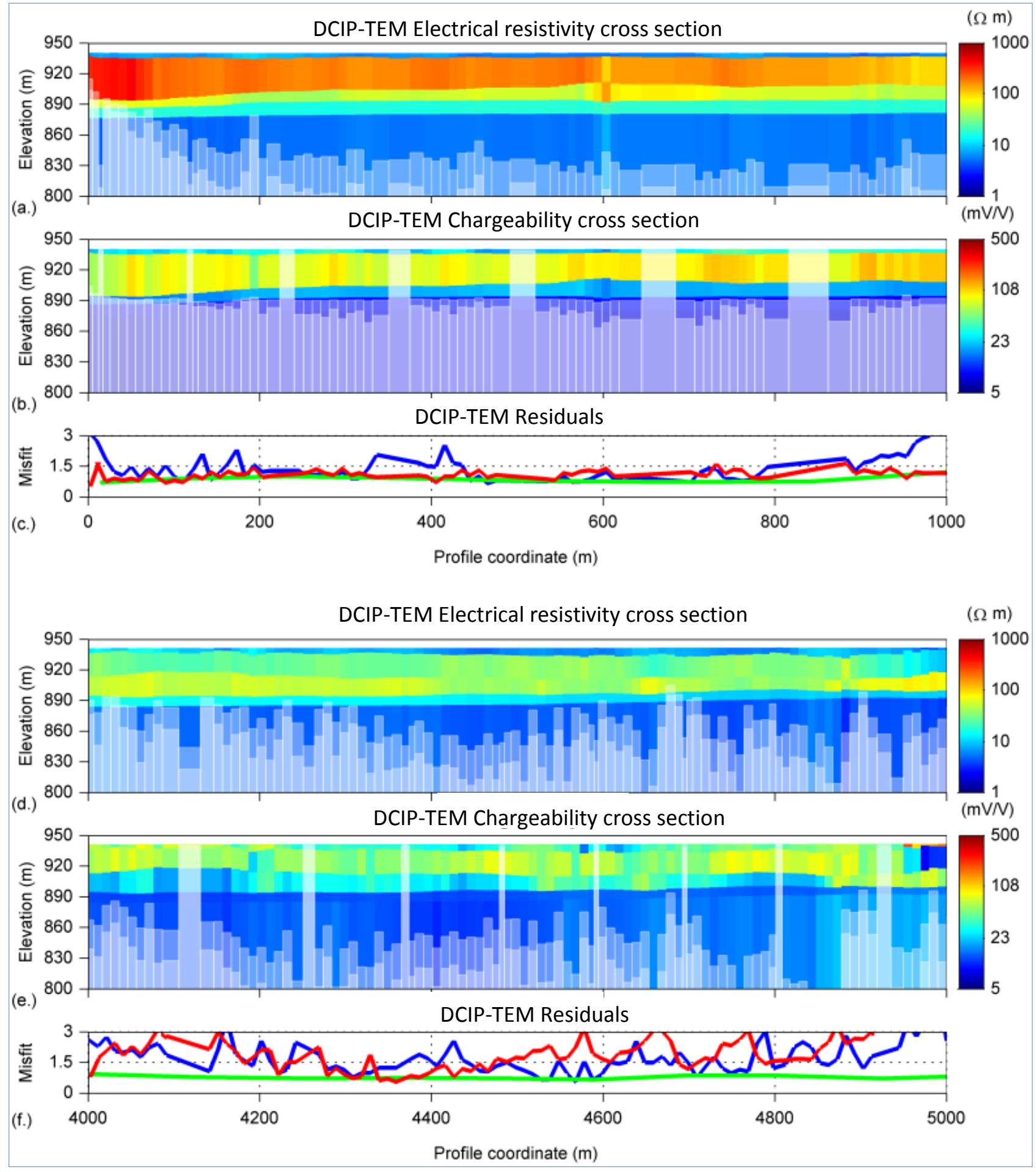

380 Figure 8: (a.) - (c.) zoom in inverse electrical resistivity cross section, inverse chargeability cross

381 section, and data residual plot respectively from joint inversion of DCIP and TEM data for distance 382 interval 0 - 1,000 m. (e.) - (f.) zoom in inverse electrical resistivity cross section, inverse 
chargeability cross section, and data residual plot respectively from joint inversion of DCIP and

TEM data for distance interval 4,000 - 5,000 m.

Thus the model cross sections from joint DCIP-TEM inversion (Figure 7 and Figure 8) show:

i. a low electrical resistivity layer about $5 \mathrm{~m}$ thick with electrical resistivity values ranging between 1 - $12.6 \Omega \mathrm{m}$ at the top;

ii. a middle high electrical resistivity lens which is about $60 \mathrm{~m}$ in the south (left hand side) and thins out towards the north (right hand side) to about $22 \mathrm{~m}$ where an electrical resistivity gradient of 200 to $30 \Omega \mathrm{m}$ is observed from south to north respectively.

iii. the high electrical resistivity lens underlain by a transition layer with thickness ranging

iv. formation resistivity of around 3.6 $\Omega \mathrm{m}$ below the high electrical resistivity and transition layers.

v. an inverse chargeability model with three distinct layers in the first half of the section and a heterogeneous mix of chargeability in the second half. Between 0 to about 3,300 $\mathrm{m}$ an approximately $5 \mathrm{~m}$ thick 20-40 mV/V chargeability layer overlies a $90-120 \mathrm{mV} / \mathrm{V}$ chargeability layer with variable thickness of about 20-40 m. This in turn is underlain by a 15-20 mV/V chargeability layer below which the chargeability values are about $7 \mathrm{mV} / \mathrm{V}$. After 3,300 m the chargeability section is more or less mixed or chequered and shows a lesser degree of layering. Chargeability values below the chequered section are about 10 $\mathrm{mV} / \mathrm{V}$.

405 The distribution of chargeability along the Kasaya Transect appears to be an indication of the 406 layering of the sediments along the transect line in addition to being correlated with the electrical 
resistivity distribution in a manner similar to the experiment of Slater and Lesmes (2002). The chargeability therefore had an added value of defining the stratification and zones where freshwater possibly infiltrated and replaced salty groundwater. Furthermore it should be understood that the main benefit of integrating DC, TEM and IP data all together is to obtain a unique model where the 411 geometry and parameter values are defined by all the available information. Thus the resulting 412 models are data driven in both the shallow part (due to DCIP data) and at depth (as a result of the 413 TEM data). Thus this is not a matter of DOI only and an attempt to give an augmented 414 interpretation in terms of changes in electrical resistivity and IP due to changes in fluid conductivity 415 with reference to the petro-physical/ textural considerations of the study area is given below.

In the experiment of Slater and Lesmes (2002), a sample of de-aired sand was first saturated with pure water (electrical resistivity $=1000 \Omega \mathrm{m}$ ) and then flushed with 33 pore volumes (25 $\mathrm{l} \mathrm{x}$ porosity) of $\mathrm{NaCl}$ (electrical resistivity $=4.54 \Omega \mathrm{m}$ ) followed by gradual reintroduction of 37 pore volumes (27 l x porosity) of pure water. Measurements of electrical resistivity and chargeability were performed during the initial introduction of $\mathrm{NaCl}$ solution and the reintroduction of pure water. From this, Slater and Lesmes (2002) observed that the bulk or formation electrical resistivity reduced with the introduction of saline water and recovered with the reintroduction of pure water. 424 They also noticed that the chargeability increased with fluid electrical resistivity in such a way that 425 the chargeability curve was almost a mirror of the electrical resistivity curve. Thus, the fact that the high chargeability distribution along the Kasaya transect appears to coincide more or less with the 427 high electrical resistivity distribution suggests that processes similar to those modelled by Slater and 428 Lesmes (2002) are at play in the Kasaya area. In other words, the high chargeability observed along 429 the Kasaya transect has to more to do with the infiltration of fresh water into a pre-existing saline 430 environment. The high chargeability section would therefore be an indicator of the physical extent 
431 of where salty water has been replaced by recent fresh water. This concept of fresh water replacing 432 pre-existing saline groundwater water under through flow conditions is also supported by Banda et 433 al. (2015) through their sediment dilution experiment in which $20 \mathrm{~g}$ of drill core sediment samples 434 from the Machile-Zambezi Basin were placed in $50 \mathrm{ml}$ centrifuge tubes and filled with deionised 435 water. They then placed the tubes in a mechanical shaker in order to dissolve mineral phases until 436 equilibrium was reached after which deionised water kept being replaced in the centrifuge tubes until the electrical conductivity was almost zero, indicative of complete removal soluble salts.

438 Nevertheless this interpretation would benefit from borehole verification through measurenments of 439 EC values and other hydrogeological data along the Kasaya Transect. However site conditions at 440 the time of the geophysical survey prevented the deployment of machinery or equipment needed for 441 the drilling of boreholes. Lack of access roads coupled with swampy conditions during the rainy season meant that any form of drilling was nearly impossible.

\subsection{Hydrogeological interpretation}

445 Available borehole records for the Kasaya area (Kameyama (2003) and Banda et al. (2014)) 446 indicate that the main aquifer material is composed of mixed and alternating sequences of sand and 447 clay. Nevertheless comparison of a coincident TEM sounding with the borehole record and 448 induction log at Kasaya (Figure 5 b) indicates that the alternating sequences of sand and clay below 449 the water table are seen as one layer with average resistivity of $3 \Omega \mathrm{m}$. Above the water table the 450 formation resistivity of the unsaturated zone was determined as $44 \Omega \mathrm{m}$ (resistivity standard 451 deviation factor $=1.07$, i.e. $\pm 3 \Omega \mathrm{m}$ ) from the TEM inverse layered earth model. The interface 452 between the $44 \Omega \mathrm{m}$ layer and the $3 \Omega \mathrm{m}$ layer at $10.6 \mathrm{~m}$ (depth standard deviation factor $=1.01$ ) was 453 taken to represent the water table although the water level reading in the borehole record at Kasaya 454 indicates the water table to be at $13.2 \mathrm{~m}$. The difference in depth between the water table recorded 
in the Kasaya borehole record and the one inferred from the TEM sounding could be as the result of either systematic and random errors when the water table was measured or the effects of the capillary fringe or a combination of both factors; it might also just be that the TEM method is not very accurate at making quantitative estimates of the water table. Nevertheless the induction log profile appears to be in agreement with the TEM sounding (Figure 5b) and given the low standard 460 deviation factors on both the electrical resistivity and the depth, the $1 \mathrm{D}$ electrical resistivity model 461 derived from the TEM sounding is considered to be very precise.

Rhoades et al. (1992) classified non saline water as having electrical conductivity (EC) of less than $700 \mu \mathrm{S} / \mathrm{cm}$, with anything above this threshold falling into one of five other degrees of salinity with the highest being the category of brines having EC greater than $45000 \mu \mathrm{S} / \mathrm{cm}$. Therefore based on equation 2, freshwater aquifers in the Kasaya area can be considered to have a formation resistivity of greater than or equal to $29.4 \Omega \mathrm{m} ; 5.6-29.4 \Omega \mathrm{m}$ for slightly to moderately saline groundwater; and 5.6 $\Omega \mathrm{m}$ or less for very saline groundwater (Zarroca et al., 2011). This classification of aquifer salinity should be viewed as representing the order of magnitude, since the petro-physical relation is bound to be site specific depending on the distribution of clay content and porosity. It can be seen from the measured pore water conductivity at Lipumpu Village, which falls at its own unique position different from the petro-physical considerations at Kasaya (Figure 5a). Therefore, the top 5 m layer with heterogeneous resistivity values ranging between 1 - $12.6 \Omega \mathrm{m}$ is probably a layer of moist top soil with varying degrees of porosity, clay content and water content; the localised lower electrical resistivity values being attributed to higher localised clay content compared to areas with 476 higher localised electrical resistivity. In addition, the high electrical resistivity lens, below the $5 \mathrm{~m}$ top soil layer, shows resistivity values greater than the $44 \Omega \mathrm{m}$ threshold for non-conducting pore water, within $1800 \mathrm{~m}$ from the edge of the Zambezi River. A possible explanation is that this region 
is composed of coarser textured sediments (sand) whose bulk electrical resistivity is governed primarily by the pore water conductivity in comparison with clayey materials whose bulk electrical resistivity is also influenced by the salts retained on the surface of the clayey minerals (Zarroca et al., 2011). Therefore the surface conductivity component of equation 1 would be significantly reduced leading to a rise in formation conductivity above the $44 \Omega \mathrm{m}$ for non-conducting pore waters. Beyond $1800 \mathrm{~m}$ from the edge of the Zambezi River, the petro-physical relation appears to hold with electrical resistivity values around $30 \Omega$ m indicative of freshwater. Below the fresh water lens, the petro-physical relation suggested by equation 1 also holds and with electrical resistivity values all below $3 \Omega \mathrm{m}$; this part of the aquifer is expected to have pore water conductivity above $20,000 \mu \mathrm{S} / \mathrm{cm}$. This distribution of electrical resistivity values along the Kasaya transect, into three distinct zones, indicates infiltration of fresh surface water into a pre-existing saline aquifer. The interaction of surface water and ground water as suggested by the geophysics is conceptualised in

491 Figure 7, and is probably driven by evapotranspiration and recharge from the Zambezi River.

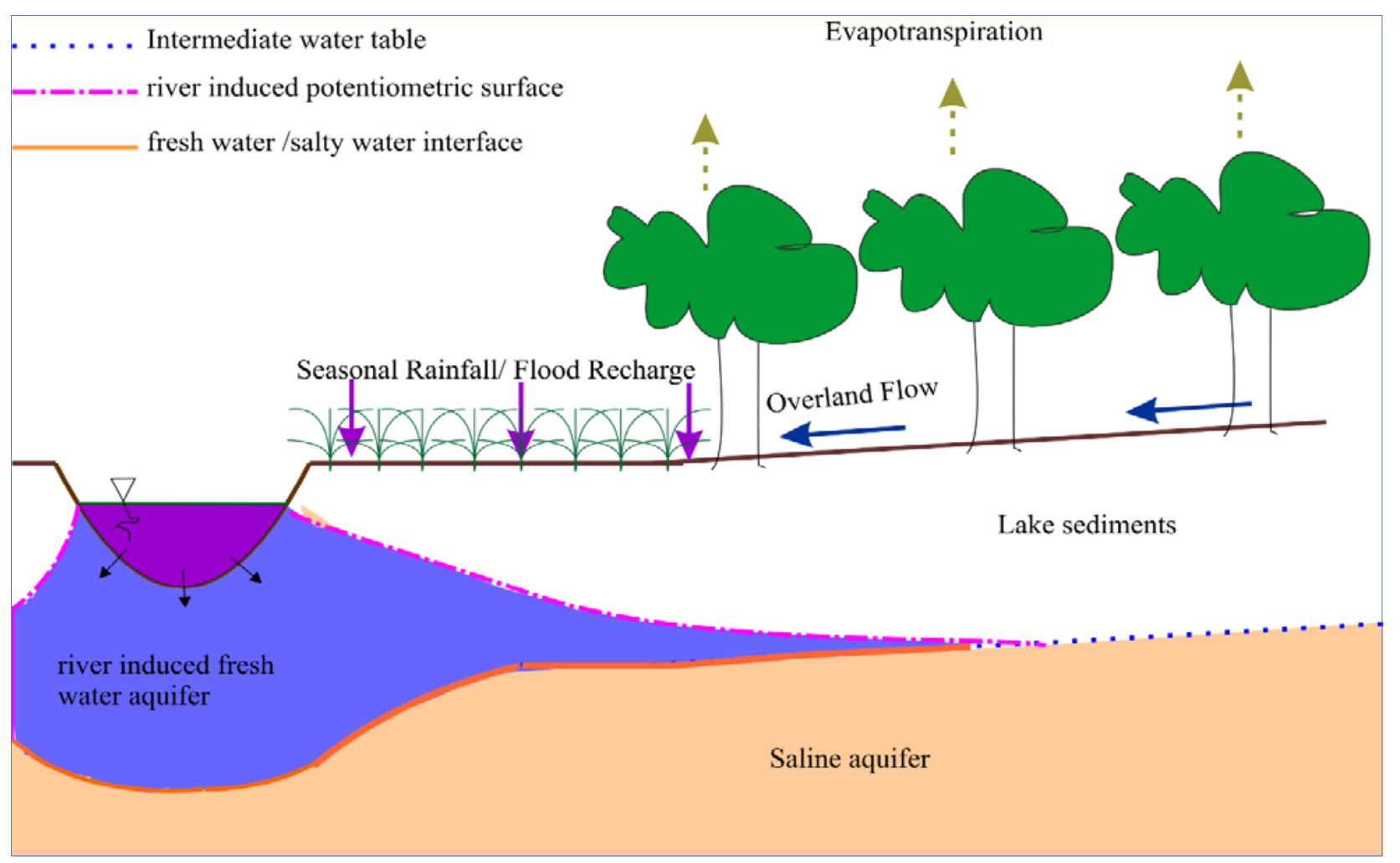


493 Figure 9: Conceptual model of surface water/ groundwater interaction in the Simalaha flood plain.

494 The major drivers are conceptualised as seasonally varying water table in the Zambezi River, 495 localised seasonal rainfall and flooding, overland flow and evapotranspiration.

497 In addition, the separation of the chargeability section (Figure 7b) mid-way into a well layered part $498(0-3,300 \mathrm{~m})$ and a chequered part $(3,300.6,600 \mathrm{~m})$ appears to correlate well with the extents of the 499 plain and forest areas. The layered chargeability section is in the plain whereas the chequered 500 chargeability section is in the forest. The reason for the high chargeability values and their 501 distribution is unknown.

\subsection{Regional scale perspectives}

504 The landscape of the Machile-Zambezi Basin comprises a southern central low lying area (elevation between 900 - $950 \mathrm{~m}$ amsl) surrounded by moderate relief hilly areas from southeast to southwest in a clockwise direction. The drainage network is such that all streams flow from the hilly areas into the low lying area and either terminate into alluvial fans or eventually end up into the Zambezi

508 River. It is therefore likely that the groundwater regime in the upper reaches of the stream network 509 is dominated by local flow systems with influent streams (Sophocleous, 2002). From the transition 510 between the hilly areas and the low lying area up to the Zambezi River the topography exhibits very 511 low gradient. Consequently the groundwater flow is probably dominated by intermediate and 512 regional flow systems. These interact with a seasonal flood cycle whereby the river system is 513 influent during flooding and effluent during the dry season (Main et al., 2008; Sophocleous, 2002).

514 Thus surface water / groundwater interaction in the Machile-Zambezi Basin can be said to be driven 515 by recharge in the high elevation areas and a mix of seasonally alternating exfiltration and 516 infiltration in the moderate to low relief areas. 
517 An evaluation of a satellite image encompassing the lower reaches of the Loanja River and the 518 Kasaya area (Figure 10 a) shows the main channel of the Loanja River emerging from the high 519 relief belt and broadening into an alluvial fan in the low relief region. Overlying the satellite image 520 with a mean horizontal electrical resistivity map for depth interval 0-20 $\mathrm{m}$ from the airborne TEM 521 (Figure 10 b.) shows that the alluvial fan is coincident with the higher electrical resistivity values. A 522 similar observation can also be made about the Simalaha Floodplain (Chongo et al., 2015). The lack 523 of borehole records along the Kasaya Transect makes it extremely difficult to constrain the 524 geophysical result to geomorphological and hydro-chemical features. However Chongo et al. (2015) 525 do give an interpretation of the regional electrical resistivity distribution based on textural and pore 526 fluid considerations that in general associate high electrical resistivity values with coarser sediments 527 and low groundwater salinity; and low electrical resistivity values with intercalations of finer and 528 coarser sediments and high groundwater salinity as illustrated in Table 1 below. 


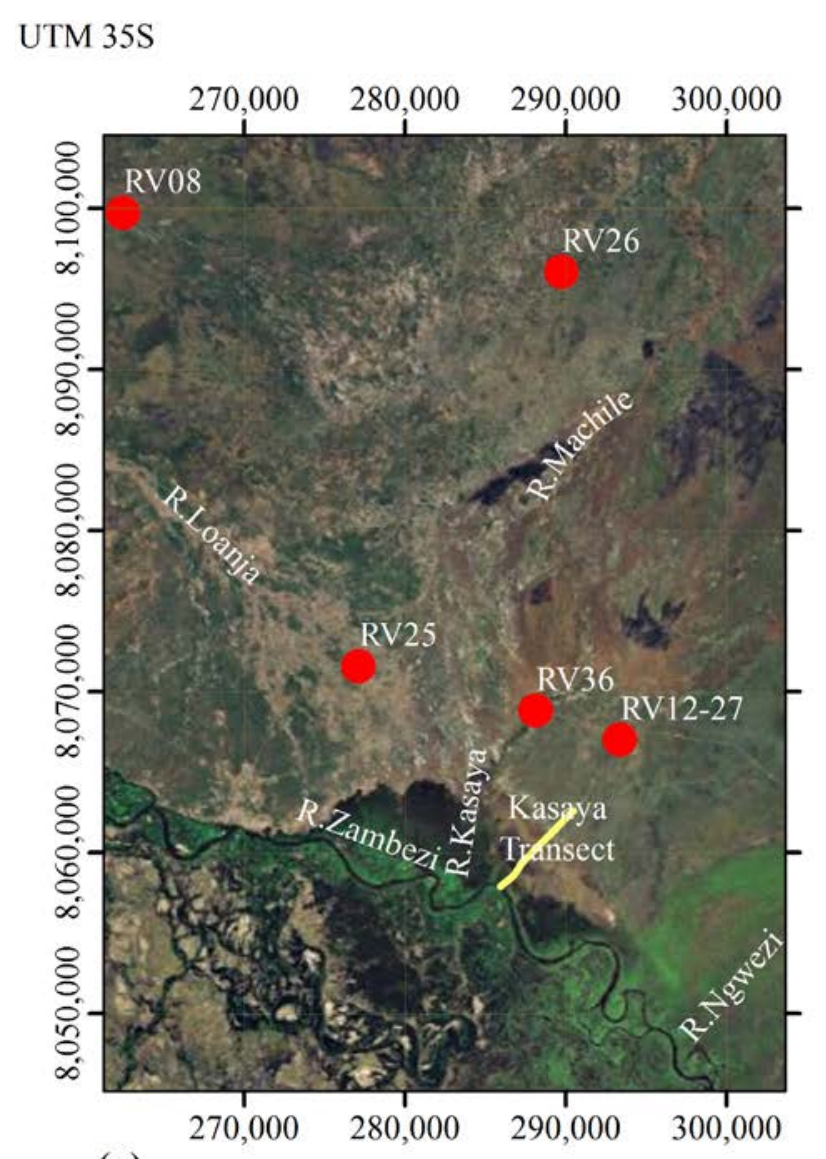

530

(a)

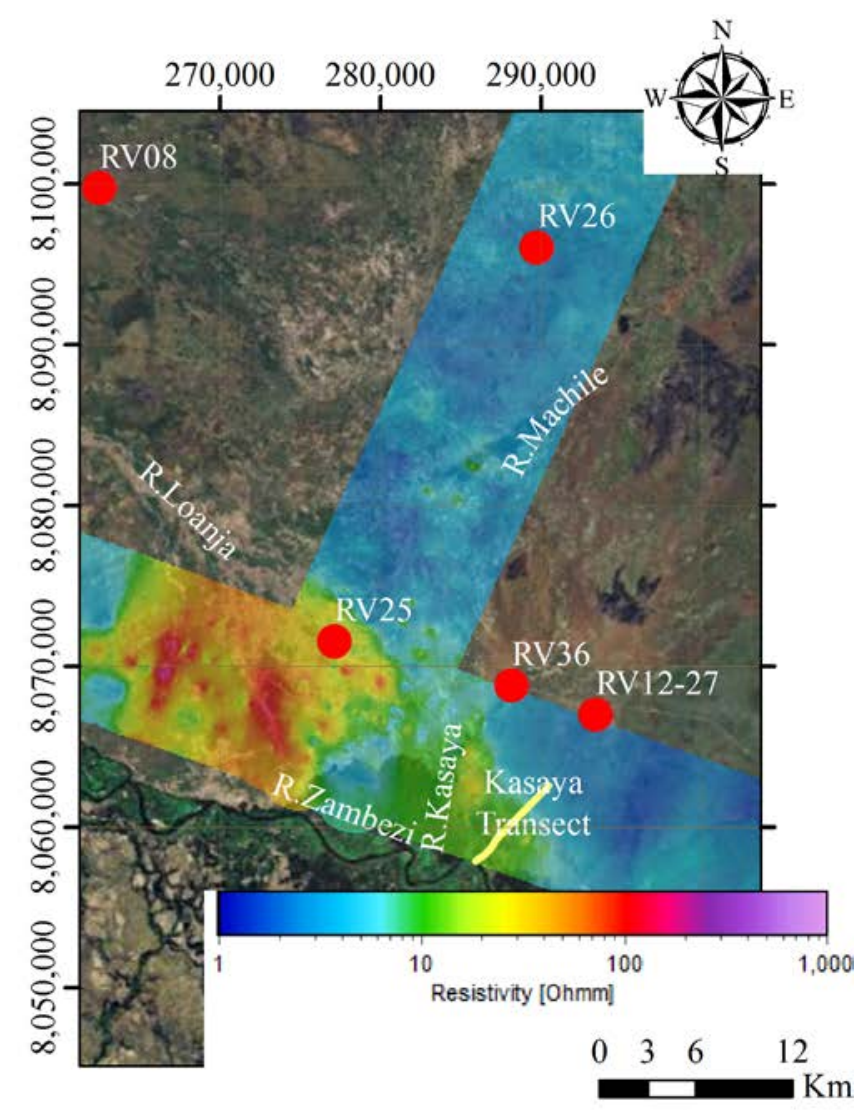

(b)

531 Figure 10: (a) Satellite imagery (ESRI worldly 2D) showing termination of Loanja River into an

532 alluvial fan in the Sesheke area, south-western Zambia. (b) Superimposition of horizontal mean

533 resistivity map for depth interval 0-20 m onto an ESRI worldly 2D Imagery.

Table 1: Correlation of formation electrical resistivity, pore water conductivity and lithology for available complete borehole records in the Machile-Zambezi Basin (Chongo et al., 2015). 


\begin{tabular}{|c|c|c|c|c|c|c|}
\hline \multirow[b]{2}{*}{ Borehole } & \multicolumn{2}{|c|}{ Location [UTM 35S] } & \multirow{2}{*}{$\begin{array}{c}\text { Pore Water } \\
\text { Conductivity } \\
{[\mu \mathrm{S} / \mathrm{cm}]}\end{array}$} & \multirow{2}{*}{$\begin{array}{c}\text { Formation } \\
\text { Resistivity }[\Omega \mathrm{m}]\end{array}$} & \multirow[b]{2}{*}{ Lithology } & \multirow[b]{2}{*}{ Category } \\
\hline & $\begin{array}{l}\text { Northing } \\
{[\mathrm{m}]}\end{array}$ & $\begin{array}{l}\text { Easting } \\
{[\mathrm{m}]}\end{array}$ & & & & \\
\hline RV_31 & 8098183.40 & 237931.96 & 372.24 & 179.48 & Sand & Freshwater \\
\hline RV_08 & 8099759.76 & 262479.77 & 577.80 & 99.31 & $\begin{array}{l}\text { Clayey Sand } \\
\text { and sandstone }\end{array}$ & Freshwater \\
\hline RV_29 & 8076339.01 & 211449.36 & 459.53 & 32.75 & $\begin{array}{l}\text { Sandstone/ } \\
\text { Basalt }\end{array}$ & Freshwater \\
\hline RV_12_02 & 8137425.81 & 299048.19 & 466.58 & 32.52 & $\begin{array}{l}\text { Sand/ } \\
\text { Sandstone }\end{array}$ & Freshwater \\
\hline RV_36 & 8068825.60 & 288165.00 & 636.02 & 24.19 & $\begin{array}{l}\text { Sand/ } \\
\text { Sandstone }\end{array}$ & Feshwater \\
\hline RV_01 & 8070051.34 & 231262.64 & 2220.91 & 8.74 & Sandy Clay & Salty water \\
\hline RV_26 & 8096066.40 & 289747.90 & 4659.35 & 5.66 & Clayey sand & Salty water \\
\hline
\end{tabular}

5444 Conclusion

545 A combination of TEM and DCIP measurements processed under joint inversion provided insight 546 into the nature of surface water / groundwater interaction on the northern bank of the Zambezi River 547 at Kasaya in southern Zambia. To our knowledge, this is the first time that joint inversion of TEM 548 and DCIP data has been conducted. The joint inversion showed a fresh water lens about $6.6 \mathrm{~km}$ in 549 length from the edge of the Zambezi River. This was found to be about $60 \mathrm{~m}$ thick at the interface 550 with the river and slowly thinned out further away from the river until it reached a thickness of 551 about $22 \mathrm{~m}$ at the end of the transect line. The fresh water lens is postulated to have had been 552 produced by a combination of river interaction with the aquifer and influenced by 553 evapotranspiration. On a sub-regional scale, the hilly and higher elevation areas of the Machile 554 Zambezi Basin act as recharge areas with influent streams, whereas the low lying areas interact with 555 a seasonal flood cycle whereby the river system is influent during flooding and effluent during the dry season. 
Finally, the combination of DCIP and TEM data in a joint inversion produced better inverse models 558 with well resolved model parameters based on DOI considerations. The TEM method was better at resolving electrical resistivities and thicknesses for the deeper layers whereas the DC LCI produced inverse models with well resolved electrical resistivities and layer thicknesses in the shallow sub 561 surface but could not resolve these parameters at well enough at depth. However the DC method provided more data density. Joint inversion of DCIP and TEM data thus produced a result with the benefits of both high spatial density and good determination of electrical resistivities and layer thicknesses both in the shallow subsurface and the deeper subsurface. Including IP data in the inversion had the added value of indicating the stratification and zones where fresh surface water has probably infiltrated into the sub surface and replaced salty groundwater.

Acknowledgements

569 We are grateful to the Governments of the Republic of Zambia and the Kingdom of Denmark for sponsoring this research under the capacity building initiative for the Zambian water sector though 571 the University of Zambia. Special thanks also go to Dr. Chisengu Mdala, Lecturer in Geophysics at 572 the University of Zambia and proprietor of Azurite Water Resources (Ltd) for allowing his field 573 technician James Zulu to accompany us if the field to collect the CVES and TEM data and to Ingrid 574 Mugamya at the UNZA IWRM Centre for logistical support. Furthermore we are grateful to Erik 575 Lange from DTU for facilitating the meeting with Kurt Sørensen of SkyTEM that enabled us to 576 borrow their WalkTEM instrument for our fieldwork. We would also like to thank Kebby Kapika 577 (District Water Officer -Sesheke, Western Province, Zambia), Mweemba Sinkombo (District Water 578 Officer -Nalolo, Western Province, Zambia) and the community at Kasaya for moral and physical 579 support during the field measurements. Finally we would like to thank the Hydro-geophysics group 580 at Aarhus University for assistance during processing and inversion of the TEM and CVES datasets. 
ABEM(a), 2012. Terrameter LS User's Guide. ABEM Geophysics, Stockholm, p. 42. ABEM(b), 2014. WalkTEM User's Guide. ABEM Geophysics, Stockholm, p. 42.

Aizebeokhai, A.P., 2010. 2D and 3D geoelectrical resistivity imaging: Theory and field design.

Albouy, Y., Andrieux, P., Rakotondrasoa, G., Ritz, M., Descloitres, M., Join, J.L., Rasolomanana,

E., 2001. Mapping coastal aquifers by joint inversion of DC and TEM soundings - Three case histories. Ground Water 39, 87-97.

Aristodemou, E., Thomas-Betts, A., 2000. DC resistivity and induced polarisation investigations at a waste disposal site and its environments. J. Appl. Geophys. 44, 275-302.

Auken, E., Christiansen, A.V., Jacobsen, B.H., Foged, N., Sorensen, K.I., 2005. Piecewise 1D laterally constrained inversion of resistivity data. Geophysical Prospecting 53, 497-506.

Auken, E., Christiansen, A.V., Kirkegaard, C., Fiandaca, G., Schamper, C., Behroozmand, A.A.,

Binley, A., Nielsen, E., Efferso, F., Christensen, N.B.i., Sorensen, K., Foged, N., Vignoli, G., 2014. An overview of a highly versatile forward and stable inverse algorithm for airborne, ground-based and borehole electromagnetic and electric data. Exploration Geophysics.

Banda, K.E., Jakobsen, R., Gottwein, P.B.-., Nyambe, I., Laier, T., Larsen, F., 2015. Identification and evaluation of hydro-geochemical processes in the groundwater environment of Machile Basin, western Zambia Unpublished results. Technical University of Denmark, 2500kgs-Lynby, Denmark, Lynby, Denmark, p. 50.

Banda, K.E., Jakobsenc, R., Gottwein, P.B.-., Murrayd, A.S., Nyambe, I., Larsen, F., 2014. The groundwater, Unpublished results. Geological Survey of Denmark and Greenland, p. 47. 
604 Bauer, P., Supper, R., Zimmermann, S., Kinzelbach, W., 2006. Geoelectrical Imaging of 605 Groundwater Salinisation in the Okavango Delta, Botswana. J. Appl. Geophys. 60, 126-141.

606 Behroozmand, A.A., Auken, E., Fiandaca, G., Christiansen, A.V., 2012. Improvement in MRS 607 parameter estimation by joint and laterally constrained inversion of MRS and TEM data. 608 Geophysics 77.

609 Bertin, J., Loeb, J., 1969. Transients and field behaviour in induced polarization. Geophysical 610 Prospecting 17, 488-510.

611 Binley, A., Kemna, A., 2006. DC Resistivity and Induced Polarization Methods, in: Rubin, Y., 612 Hubbard, S.S. (Eds.), Hydrogeophysics. Springer.

613 Brodie, R., Sundaram, B., Tottenham, R., Hostetler, S., Ransley, T., 2007. An Overview of Tools 614 for Assessing Groundwater-Surface Water Connectivity, in: Forestry, D.o.A.i.a. (Ed.). Bureau of 615 Rural Sciences, Canberra. .

616 Chongo, M., Christiansen, A.V., Tembo, A., Banda, K.E., Nyambe, I.A., Larsen, F., Bauer617 Gottwein, P., 2015. Airborne and Ground based Transient Electromagnetic Mapping of 618 Groundwater Salinity in the Machile-Zambezi Basin, South-western Zambia. . Near Surface 619 Geophysics 13, $383-395$.

620 Christiansen, A.V., Auken, E., 2012. A global measure for depth of investigation. Geophysics 77.

621 Christiansen, A.V., Auken, E., Foged, N., Sorensen, K.I., 2007. Mutually and laterally constrained 622 inversion of CVES and TEM data: a case study. Near Surface Geophysics 5, 115-123.

623 Christiansen, A.V., Esben, A., Sørensen, K., 2006. The Transient Electromagnetic Method, in: 624 Kirsch, R. (Ed.), Groundwater Geophysics, A Tool for Hydrogeology. Springer, Flintbek, Germany. 625 Dahlin, T., 2001. The development of DC resistivity imaging techniques. Computers and 626 Geosciences 27, 1019-1029. 
Dahlin, T., Leroux, V., Nissen, J., 2002. Measuring techniques in induced polarisation imaging. J. Appl. Geophys. 50, 279-298.

Dahlin, T., Zhou, B., 2006. Multiple-gradient array measurements for multichannel 2D resistivity imaging. Near Surface Geophysics 4, 113-123.

631 Danielsen, J.E., Auken, E., Jørgensen, F., Søndergaard, V., Sørensen, K.I., 2003. The application of 632 the transient electromagnetic method in hydrogeophysical surveys. J. Appl. Geophys. 53, 181-198.

633 Danielsen, J.E., Dahlin, T., Owen, R., Mangeya, P., Auken, E., 2007. Geophysical and 634 Hydrogeologic Investigation of Groundwater in the Karoo Stratigraphic Sequence at Sawmills in 635 Nothern Matebeleland, Zimbabwe: A Case History. Hydrogeology Journal 15, 945-960.

636 ESRI, 2014. World Imagery.

637 Ezersky, M., Legchenko, A., Al-Zoubi, A., Levi, E., Akkawi, E., Chalikakis, K., 2011. TEM study 638 of the geoelectrical structure and groundwater salinity of the Nahal Hever sinkhole site, Dead Sea 639 shore, Israel. J. Appl. Geophys. 75, 99-112.

640 Fiandaca, G., Auken, E., Christiansen, A.V., Gazoty, A., 2012. Time-domain-induced polarization: 641 Full-decay forward modeling and 1D laterally constrained inversion of Cole-Cole parameters. 642 Geophysics 77, E213-E225.

643 Fiandaca, G., Ramm, J., Binley, A., Gazoty, A., Christiansen, A.V., Auken, E., 2013. Resolving 644 spectral information from time domain induced polarization data through 2-D inversion. 645 GEOPHYSICAL JOURNAL INTERNATIONAL 192, 631-646.

646 Gazoty, A., Fiandaca, G., Pedersen, J., Auken, E., Christiansen, A.V., 2012a. Mapping of landfills 647 using time-domain spectral induced polarization data: the Eskelund case study. Near Surface 648 Geophysics 10, 575-586. 
649 Gazoty, A., Fiandaca, G., Pedersen, J., Auken, E., Christiansen, A.V., 2013. Data repeatability and 650 acquisition techniques for time-domain spectral induced polarization. Near Surface Geophysics 11, $651 \quad 391-406$.

652 Gazoty, A., Fiandaca, G., Pedersen, J., Auken, E., Christiansen, A.V., Pedersen, J.K., $2012 b$. 653 Application of time domain induced polarization to the mapping of lithotypes in a landfill site. 654 Hydrology and Earth System Sciences 16, 1793-1804.

655 Geonics, 2006. PROTEM 47D Operating Manual for 20/30 Gate Model. Geonics Limited, Ontario, 656 Canada.

657 GEOTECH, 2011. Survey and logistcs report on a helicopter borne versatile time domain 658 electromagnetic survey on the Zambezi River Basin Kazungula Zambia for Ministry of Energy and 659 Water Development (Republic of Zambia). GEOTECH AIRBORNE LIMITED, West Indies, p. 20. 660 Guerin, R., Descloitres, M., Coudrain, A., Talbi, A., Gallaire, R., 2001. Geophysical surveys for 661 identifying saline groundwater in the semi-arid region of the central Altiplano, Bolivia. Hydrol. 662 Process. 15, 3287-3301.

663 Harthill, N., 1976. Time-Domain Electromagnetic Sounding. IEEE Transactions on Geoscience 664 Electronics 14, 256-260.

665 Johnson, I.M., 1984. Spectral induced polarization parameters as determined through time-domain 666 measurements. Geophysics 49.

667 Kameyama, N., 2003. Completion Report: JICA borehole drilling project-Sesheke. Ministry of 668 Energy and Water Development, Lusaka.

669 Kirsch, R., 2009. Groundwater geophysics : a tool for hydrogeology.

670 Loke, M.H., 1999. Electrical Imaging Surveys for Environmental and Engineering Studies, A 671 Practical Guide to 2-D and 3-D Surveys, Malaysia. 
672 Loke, M.H., Chambers, J.E., Rucker, D.F., Kuras, O., Wilkinson, P.B., 2013. Recent developments

673 in the direct-current geoelectrical imaging method. J. Appl. Geophys. 95, 135-156.

674 Main, M.P.L., Moore, A.E., Williams, H.B., Cotterill, F.P.D., 2008. The Zambezi River. Large 675 Rivers: Geomorphology and Management, 311-332.

676 Marescot, L., Monnet, R., Chapellier, D., 2008. Resistivity and induced polarization surveys for 677 slope instability studies in the Swiss Alps. ENGINEERING GEOLOGY 98, 18-28.

678 Milosevic, N., Thomsen, N.I., Juhler, R.K., Albrechtsen, H.J., Bjerg, P.L., 2012. Identification of 679 discharge zones and quantification of contaminant mass discharges into a local stream from a 680 landfill in a heterogeneous geologic setting. Journal of Hydrology 446, 13-23.

681 Mualem, Y., Friedman, S.P., 1991. THEORETICAL PREDICTION OF ELECTRICAL682 CONDUCTIVITY IN SATURATED AND UNSATURATED SOIL. Water Resources Research $68327,2771-2777$.

684 Nabighian, M.N., 1991. Electromagnetic Methods in Applied Geophysics Vol. 2, Electromagnetic 685 Methods in Applied Geophysics Vol. 2.

686 Nassir, S.S.A., Loke, M.H., Lee, C.Y., Nawawi, M.N.M., 2000. Salt-water intrusion mapping by 687 geoelectrical imaging surveys. Geophysical Prospecting 48, 647-661.

688 Oldenburg, D.W., Li, Y.G., 1999. Estimating depth of investigation in dc resistivity and IP surveys. 689 Geophysics 64, 403-416.

690 Pelton, W.H., Ward, S.H., Hallof, P.G., Sill, W.R., Nelson, P.H., 1978. Mineral discrimination and 691 removal of inductive coupling with multifrequency IP. Geophysics 43, 588-609.

692 Rhoades, J.D., Kandiah, A., Mashali, A.M., 1992. The use of saline waters for crop production 693 FAO irrigation and drainage paper 48. FOOD AND AGRICULTURE ORGANIZATION OF THE 694 UNITED NATIONS, Rome. 
695 Rhoades, J.D., Manteghi, N.A., Shouse, P.J., Alves, W.J., 1989. SOIL ELECTRICALCONDUCTIVITY AND SOIL-SALINITY - NEW FORMULATIONS AND CALIBRATIONS. SOIL SCIENCE SOCIETY OF AMERICA JOURNAL 53, 433-439.

700 Rubin, Y., Hubbard, S.S., 2006. Hydrogeophysics. Springer.

701 Shalem, Y., Weinstein, Y., Levi, E., Herut, B., Goldman, M., Yechieli, Y., 2014. The extent of 702 aquifer salinization next to an estuarine river, an example from the eastern mediterranean. 703 Hydrogeology Journal.

704 Shanafield, M., Cook, P.G., 2014. Transmission losses, infiltration and groundwater recharge 705 through ephemeral and intermittent streambeds: A review of applied methods. Journal of Hydrology $706511,518-529$.

707 Slater, L.D., Lesmes, D., 2002. IP interpretation in environmental investigations. Geophysics 67, $708 \quad 77-88$.

709 Sonkamble, S., Kumar, V.S., Amarender, B., Dhunde, P.M., Sethurama, S., Kumar, K.R., 2014. 710 Delineation of fresh aquifers in tannery belt for sustainable development - A case study from 711 southern India. J. Geol. Soc. India 83, 279-289.

712 Sophocleous, M., 2002. Interactions between groundwater and surface water: the state of the 713 science. Hydrogeology Journal 10, 52-67.

714 Spies, B.R., 1989. Depth of investigation in electromagnetic sounding methods. Geophysics 54, $715 \quad 872-888$.

716 Titov, K., Komarov, V., Tarasov, V., Levitski, A., 2002. Theoretical and experimental study of time 717 domain-induced polarization in water-saturated sands. J. Appl. Geophys. 50, 417-433. 

Ngomseu, C., Galaup, S., Rejiba, F., Begassat, P., 2011. Mapping of contaminant plumes with geoelectrical methods. A case study in urban context. J. Appl. Geophys. 75, 738-751.

Vilhelmsen, T.N., Behroozmand, A.A., Christensen, S., Nielsen, T.H., 2014. Joint inversion of aquifer test, MRS, and TEM data. Water Resources Research 50, 3956-3975.

Weller, A., Slater, L., Nordsiek, S., 2013. On the relationship between induced polarization and surface conductivity: Implications for petrophysical interpretation of electrical measurements. Geophysics 78, D315-D325.

Westbrook, S.J., Rayner, J.L., Davis, G.B., Clement, T.P., Bjerg, P.L., Fisher, S.T., 2005. Interaction between shallow groundwater, saline surface water and contaminant discharge at a seasonally and tidally forced estuarine boundary. Journal of Hydrology 302, 255-269.

Winter, T.C., 1999. Relation of streams, lakes, and wetlands to groundwater flow systems. Hydrogeology Journal 7, 28-45. investigation method based on a modified fixed central-loop system. J. Appl. Geophys. 76, 23-32. Zarroca, M., Bach, J., Linares, R., Pellicer, X.M., 2011. Electrical methods (VES and ERT) for identifying, mapping and monitoring different saline domains in a coastal plain region (Alt Emporda, Northern Spain). Journal of Hydrology 409, 407-422.

Zarroca, M., Linares, R., Rodellas, V., Garcia-Orellana, J., Roqué, C., Bach, J., Masqué, P., 2014.

Delineating coastal groundwater discharge processes in a wetland area by means of electrical 738 resistivity imaging, 224Ra and 222Rn. Hydrol. Process. 28, 2382-2395.

739 Zarroca, M., Linares, R., Velásquez-López, P.C., Roqué, C., Rodríguez, R., 2015. Application of 740 electrical resistivity imaging (ERI) to a tailings dam project for artisanal and small-scale gold 741 mining in Zaruma-Portovelo, Ecuador. J. Appl. Geophys. 113, 103-113. 
742 Zhou, S., Yuan, X., Peng, S., Yue, J., Wang, X., Liu, H., Williams, D.D., 2014. Groundwater743 surface water interactions in the hyporheic zone under climate change scenarios. Environmental 744 Science and Pollution Research.

745

746 